Original Research Paper

\title{
Conversion of a Conventional Vehicle into a Battery-Super Capacitor Hybrid Vehicle
}

\author{
${ }^{1}$ Anuradha Herath, ${ }^{2}$ Pasan Gunawardena, \\ ${ }^{1}$ Vimukthi Randeny, ${ }^{1}$ Sasiranga De Silva and ${ }^{1}$ Nirosh Jayaweera \\ ${ }^{I}$ Department of Mechanical Engineering, University of Moratuwa, Sri Lanka \\ ${ }^{2}$ Department of Electronics and Telecommunication Engineering, University of Moratuwa, Sri Lanka
}

Article history

Received: 18-07-2018

Revised: 03-09-2018

Accepted: 11-10-2018

Corresponding Author:

Nirosh Jayaweera

Department of Mechanical

Engineering, University of

Moratuwa, Sri Lanka

Email: nirosh.jayaweera@gmail.com

\begin{abstract}
The use of a super capacitor pack parallel with a battery pack in electric vehicles can have effects on the battery life as well as on the driving range of the vehicle. In this research a conventional IC engine vehicle was converted into a motor driven electric vehicle. The converted vehicle was tested on a drive cycle defined to match urban pattern. To extend the range of the converted vehicle, a novel battery-super capacitor system had been proposed with a novel algorithm to determine when to charge and discharge batteries and super capacitors, according to the driving conditions such as acceleration and deceleration. Software simulations were performed taking the Urban Dynamometer Drive Schedule (UDDS) as the test drive cycle. Simulations results of the proposed system and the conventional battery electric vehicle system were compared to claim the performance of the proposed algorithm. The novel system is capable of reducing the strain on the batteries while extending the range of the vehicle compared to the conventional battery electric vehicle.
\end{abstract}

Keywords: Battery-Super Capacitor, Electric Vehicle, Range Extension

\section{Introduction}

Global warming causes ecological damage. It is a result of "Greenhouse effect" induced by the presence of carbon dioxide and other greenhouse gases. Motor vehicles emit $30 \%$ to $85 \%$ of all man-made air pollutants in the large urban areas in developing countries, depending on the level of motorization (Faiz, 1993). Therefore it was essential to find an alternative transport method, which is environmentally friendly. A numerous research had been done and currently being done on low carbon emission vehicles, which can provide a solution to the increasing air pollution caused by the transport sector. Using of electric motors as the prime mover of electric vehicles has advantages such as higher efficiency than internal combustion engines and regenerative braking ability (Smith, 2010).

Many companies had manufactured electric vehicles for over 100 years. The first electric vehicle is a converted Hillman Sociable tricycle created by M. Raffard in France in 1881 (Anderson and Anderson, 2004). Recent years have shown a renewed interest in hybrid and fully electric vehicles worldwide. With prices of crude oil on the rise and increasing awareness of environmental pollution as well as emission regulations being enforced by several environmental protective agencies such as California Air Research Board (CARB) and united States Environmental Protective agency (EPA), it is natural for automotive manufacturers and motorists themselves to come up with more efficient and environmentally friendly means of propulsion (USEPA, 2005).

Despite hybrid and fully electric vehicles gaining popularity, these vehicles still remain beyond the grasp of many worldwide. Their chief cost component being the advanced power train, these vehicles have to compete with more luxurious conversional automobiles in the same price range in many world markets. Many experiments had been done on electric driven vehicles and hybrid vehicles throughout the history. Even at the present, many reputed car manufacturing companies such as Toyota, Honda, General Motors and Vauxhall are continuously doing researches and experiments on developing hybrid and fully electric vehicles.

In the recent past with the rapid increase of the number of vehicles, the gas emitted has increased the environmental pollution. To reduce the amount of exhaust gases electric vehicles, which are powered by renewable energy sources can be used as they can run in 
urban environments with less emission (Mierlo et al., 2006). This has an additional advantage of being a zero emission vehicle in future when the electricity is fully generated by renewable energy sources.

\section{Literature Review}

\section{Energy Storage Systems}

Energy storage systems capture energy once energy is produced. The captured energy can be used at a later time. Different types of energy storage systems had been used in electric vehicles over the past century.

Lead acid batteries were the most common energy storage devices which had been used in electric vehicles in the past century despite having a very lower energy density and shorter cycle life compared to the modern batteries such as Lithium-ion and Nickel metal Hydride batteries (Hannan et al., 2014). The low price of lead acid batteries made them popular in electric vehicles. Mechanical flywheels had also been used as energy storage devices (Larmine, 2003). The advantage of having a high power density of flywheels is cancelled out by its very low energy density. Therefore flywheels are mostly suitable in situations where quick charge and discharge of energy is required (Vasques et al., 2010).

NiMH batteries have high energy densities and resistance to abuse, but they have a high discharge rate. Polymer Li-ion batteries own power densities up to four times as much as lead-acid batteries (burke, 2005). Therefore now Li-ion batteries have become the most viable option as an energy storage device in most of the commercial electric vehicles. Table 1 indicates characteristics of different energy storage devices.

Super capacitors are a high power density energy storage system which has drawn the attention of many recent studies. Super Capacitors (SC), are in many ways, similar to batteries. The major difference is that unlike batteries, super capacitors cannot store large amounts of energy for extended periods, i.e they have low energy density (Lukic et al., 2008) (Thounthong et al., 2009).

Fossil fuel still remains the best in the terms of energy and power densities required for automobiles. Therefore when considering the present situation, combining two or more power sources is desirable than using battery electric power as the sole energy supply for an automobile
(Embrandiri et al., 2011). Usually a combination of a high power density energy storage device (quick response) and a high energy density energy storage device (longer range) is desirable in automotive applications. A few energy source combinations proposed as suitable for hybrid electric vehicles are battery and electric double layer capacitors (EDLC), Fuel Cells (FC) and battery, FC and EDLC, Compressed Air Energy Storage (CAES) and Battery, CAES and EDLC, battery and flywheel, battery and Superconducting Magnetic Energy Storage (SMES) (Brown et al., 2014; Zhao et al., 2014).

Despite the lack of studies involving super capacitors as a possible range extending device, there have been several studies in recent years so as to examine the effects of coupling a super capacitor with a battery and/or IC engine as an Auxiliary Energy Storage device (AES). A significant research had been performed by Micah Ortúzar (2010), of the Massachusetts Institute of technology. The researchers used a Go-kart chassis to test their design. However the battery and super capacitor were coupled in series, which results in a simple, yet inefficient system, certainly not beneficial for range extension. However, the MIT design provides a simplified illustration of how a super capacitor can be used in EVs in the future.

Most of the studies used series wound DC motors for propulsion. While Micah Ortúzar (2010) attempt in using regeneration, yet a software malfunction prevented the system from working. Embrandiri et al. (2011) do not attempt to harvest braking energy.

A fuel cell-super capacitor hybrid is proposed by Thounthong et al. (2009) here a small scale model was evaluated in various driving conditions. Voltage, power and current responses of FC-battery as well as FC-super capacitor units were monitored from a standstill to 1500 rpm and then for braking, the conclusion being that a FCsuper capacitor system has better characteristics and better transient response than a battery-FC hybrid system.

A new hybrid energy storage system (HESS) without a DC-DC converter interfacing the energy sources is proposed by $\mathrm{Lu}$ et al. (2007). Either the battery or SC source is connected to the vehicle motor drive via a complimentary switch pair. The efficiency has been increased and the cost has been decreased by minimizing the amount of semiconductor devices used for the system.

Table 1: Characteristics of different energy storage devices

\begin{tabular}{llllll}
\hline Type & $\begin{array}{l}\text { Energy } \\
\text { efficiency }(\%)\end{array}$ & $\begin{array}{l}\text { Energy } \\
\text { density }(\mathrm{Wh} / \mathrm{kg})\end{array}$ & $\begin{array}{l}\text { Power } \\
\text { density }(\mathrm{W} / \mathrm{kg})\end{array}$ & $\begin{array}{l}\text { Cycle life } \\
\text { (Cycles) }\end{array}$ & $\begin{array}{l}\text { Self-discharge } \\
\text { rate }\end{array}$ \\
\hline Lead-Acid & $70-80$ & $20-35$ & 25 & $200-2000$ & Low \\
Ni-Cd & $60-90$ & $40-60$ & $140-180$ & $500-2000$ & Low \\
Ni-MH & $50-80$ & $60-80$ & 220 & $<3000$ & High \\
Li-ion & $70-85$ & $100-200$ & 360 & $500-2000$ & Medium \\
Li-polymer & 70 & 200 & $250-1000$ & $>1200$ & Medium \\
Flywheel (steel) & 95 & $5-30$ & 1000 & $>20000$ & Very high \\
Flywheel (Composite) & 95 & $>50$ & 5000 & $>20000$ & Very high \\
sratucaCaC repuS & 59 & $3.0-3.9$ & 0933 & $>03333$ & hrih \\
\hline
\end{tabular}


A method of reducing the battery stress using SCs in a 500-kVA rated Uninterruptible Power Supply (UPS) is proposed in (Lahyani et al., 2013). Two DC-DC converters interfaced the two energy sources into the DC bus of the inverter, which is connected to the $230 \mathrm{~V}$ main grid. The developed control strategy monitors the shape of the load demand and the State of Charge (SoC) of the SC pack. It uses predefined power sharing principles to determine which source to be selected to give the power in a given moment.

A HESS has been proposed with the averaging concept in (Cao et al., 2012). It has reduced the required power capability of the DC-DC converter, which has ultimately reduced the size and the cost of the proposed system.

\section{Regenerative Braking Efficiency in Electric and Hybrid Electric Vehicles}

Various scenarios for which a vehicle requires deceleration and braking are diverse and cannot be examined individually. However the energy that can be recovered during braking should be examined. Regenerative braking in hybrid and fully electric vehicles can extract some of this kinetic energy. The percentage of the energy that can be extracted depends on the urgency of braking and the design of the energy recovery system itself. Due to restrictions in power density of their energy storage systems, regenerative braking in hybrid electric vehicles and fully electric vehicles are unable to recover energy as fast as mechanical braking. Thus gradual braking over a long distance is desirable. In theory if the driver wants to stop the vehicle and hit on the brake, it is possible to recover all energy except the energy lost due to frictional forces between the tires and road as well as drag and power train inefficiencies. The below calculation is simplified for clarity.

Let us first examine the energy lost during a simple deceleration of an automobile from $60 \mathrm{~km} / \mathrm{h}$ to a full stop. Numerical values have been adopted from publications on motor vehicle performance.

Assuming the average length of the vehicle is $4 \mathrm{~m}$, weight of the vehicle as $1000 \mathrm{~kg}$ and the speed of the vehicle is $60 \mathrm{~km} / \mathrm{h}$ on a dry and flat asphalt road.

Assume it come to a stop within $21 \mathrm{~m}$. (Value extrapolated from British Highway code (DT, 2007). This value does not include the distance traveled during thinking time of the driver which is estimated to be 11 $\mathrm{m})$. Assume $100 \%$ efficiency for the motor generator:

$$
\begin{aligned}
& \text { kinetic energy of the vehicle }=0.5 m v^{2} \\
& 0.5 * 1000 *(60 * 1000 / 3600)^{2}=138.89 k J
\end{aligned}
$$

The above Equation 1 shows the energy that is dissipated as heat due to friction between brake pads and discs/drums as well as being absorbed by the vehicle's suspension.

Let us now calculate the time required for the car to come to a complete stop. Assuming the average linear deceleration, Equation 2 and 3 shows the required deceleration and the stopping time of the vehicle:

$$
\begin{aligned}
& v^{2}=u^{2}+2 a x \\
& 0=(60 * 1000 / 3600)^{2}+2 a * 21 \\
& a=-6.61 \mathrm{~m} / \mathrm{s}^{2} \\
& \text { from } v=u+a t
\end{aligned}
$$$$
\text { stopping time }=t=2.52 \mathrm{~s}
$$

Energy dissipated presecond $=138.89 / 2.52=55.09 \mathrm{~kJ} / \mathrm{s}$

According to the Equation 4 the rate of energy dissipation during braking is about $55 \mathrm{~kJ} / \mathrm{s}$. The power density of Lithium ion batteries is about $400 \mathrm{~W} / \mathrm{kg}$, but the power density of super capacitors is about 2500 $\mathrm{W} / \mathrm{kg}$. Considering our above calculation, if we were to store $100 \%$ of the lost kinetic energy during deceleration, after ignoring frictional losses, we shall require a Lithium ion battery pack weighing $137 \mathrm{~kg}$. However we only require a $22 \mathrm{~kg}$ super capacitor pack.

The above example illustrated the benefits of high power density of a super capacitor. This in turn provides the added benefit of less weight. However, it is not possible to run an EV for considerable distance on super capacitors alone, as it will require a large number of cells due to its very low energy density and will be beyond economically feasibility (Mukongo, 2010).

\section{Advanced Vehicle Simulator (ADVISOR)}

The software which was used in modeling the batterysuper capacitor system in this research is ADVISOR. The Advanced Vehicle Simulator software was launched in November 1994 by the National Renewable Energy Laboratory (NREL) as an analysis tool to assist the U.S Department of energy in developing and understanding hybrid electric vehicles (Markel et al., 2002). ADVISOR has become the unofficial industry standard when it comes to vehicle power train evaluation and optimization as well as emissions estimation (Wipke, 1999). A power train can be designed using available components in the database, or custom components coded using Maltab or Simulink. A suitable power train configuration (Conventional IC engine, EV, Hybrid series) can be selected and each component can be edited and altered to meet the requirements of the user (Johnson, 2002; Senger, 1998). The designed vehicle can be driven through any of the available driving cycles a finite number of times as well as designing a custom trip by joining several different 
driving cycles. ADVISOR uses a quasi-steady approximation approach to vehicle modeling for parallel and series HEVs, pure EVs, or ICE vehicles. At each discrete time step, ADVISOR calculates the required energy at the wheels of the vehicle using a predetermined velocity profile. It then determines the amount of input energy required by each component to meet the energy requirement at the wheels.

\section{Procedure}

The Urban Dynamometer Driving Schedule also known as U.S-FP72 (Federal test procedure) schedule was used for the simulations. There it is able to map performance characteristics of each component of the vehicle and estimate the required power to achieve the required performance. Next the user can add their own power train layout and examine the deviation between the intended driving cycle performance and actual performance. The simulation was run for a vehicle which matches the specifications of an Austin mini 850. The mentioned vehicle can be used as a good representative for modern compact cars. The vehicle was assumed to be run by a motor which replaced the engine. The motor which had been used is a $10 \mathrm{~kW}$ Brushless DC (BLDC) motor (Randeny, 2015). Initially it was powered using Lead-acid batteries and once the initial test was successful Li-ion batteries were used.

As an initial step the Austin Mini 850, which was powered by the gasoline engine was converted into a motor driven vehicle. The vehicle was selected as it is a good representation of modern compact vehicles which are designed for urban driving conditions. The engine was replaced with the aforementioned motor and was powered by batteries. The converted vehicle is represented in Fig. 2. Apart from the calculations, ADVISOR was used as an assist in determining the required power of the motor. For the analysis of the performance of battery supercapacitor hybrid system, more priority was given to the data obtained by ADVISOR.

\section{Proposed Battery-Super Capacitor Hybrid System}

As discussed in the Table 1, Li-ion batteries have higher energy densities and moderate power densities. These qualities have the ability to provide the vehicle with a sufficient range per full charge (using a battery pack with considerably a lower weight than lead acid batteries) and moderate accelerations. However the moderate power density of the Li-ion batteries restricts the vehicle having high acceleration as well as higher regenerative braking efficiency. Majority of the regenerated braking power is lost at the wheel due to the friction and heat and the Li-ion batteries are not capable of harvesting most of regenerated energy (especially at quicker decelerations) due to its lower power density.

To mitigate the problems associated with single energy source, HESS are introduced. Various algorithms are used to determine the share of power among the combined energy storages. (Guidi et al., 2009) has proposed at least one of the following should be achieved it to be effective control strategy. (1) Maximize driving range; (2) Minimize component stress, resulting in maximize life expectance of the HESS; (3) Maintain steady power flow by supplying instantaneous load demand; (4) Optimal power sharing based on the state of the individual energy sources.

By considering the above facts a control algorithm to increase the EV battery life and increase the EV drive range is proposed in this study. It is achieved by reducing the sudden upward and downward current spikes which are drawn from and received by the battery while accelerating and decelerating during regenerative braking intervals. To accomplish this, a Super Capacitor (SC) pack is combined with the EV battery. SCs are widespread in the power industry due to their high pulse current, reciprocal charge-discharge ability, high cycling capability, low Equivalent Series Resistance (ESR) and recyclability. Heat production due to $\mathrm{I} 2 \mathrm{R}$ losses within the HESS is also reduced when a SC pack is used with the battery (Kerns et al., 2017). However, the main objective of the use of SCs still remains as buffering the power between the battery pack and the motor drive, due to its low energy density (Ju et al., 2014).

The control algorithm determines which source to be chosen to get the required power when the vehicle is accelerating and which source to be chosen to give the excess power when the vehicle is decelerating and regenerating. The control algorithm is focused on getting the maximum use of SC pack. SC packs have more life cycles than li-iron batteries (Khaligh and $\mathrm{Li}, 2010$ ). Therefore control algorithm allows the SC pack to absorb the sudden excess energy and give that energy in the future power demands.

Therefore the following algorithm mentioned in Fig. 1 is proposed as a method to use a battery-super capacitor hybrid system, which is capable of providing higher accelerations and higher regenerative braking efficiency. (Here the acceleration and the deceleration mentioned as ' $a$ ' and ' $b$ ' are predefined threshold values and can be found in Table 2).

According to the proposed algorithm when the vehicle experiences a rapid acceleration or a rapid deceleration, the dominant energy storage system would be super capacitors, while in the normal driving conditions and slow acceleration and deceleration conditions, the dominant energy storage system would be the Li-ion batteries. Here the situation where the acceleration is zero (i.e., vehicle travels at a constant velocity) constant current 
will be drawn out from the batteries and super capacitors according to the speed of the vehicle.

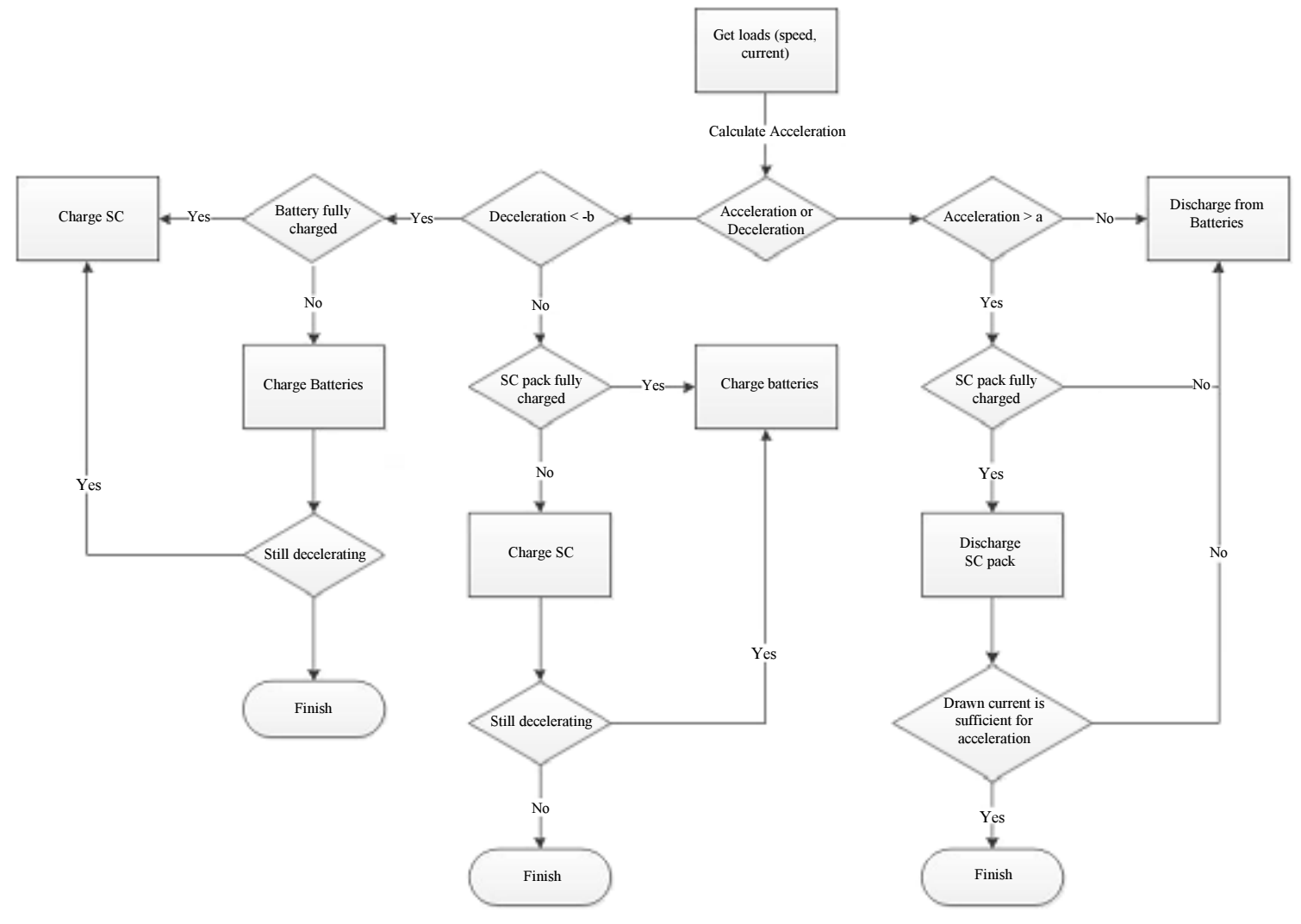

Fig. 1: Proposed algorithm

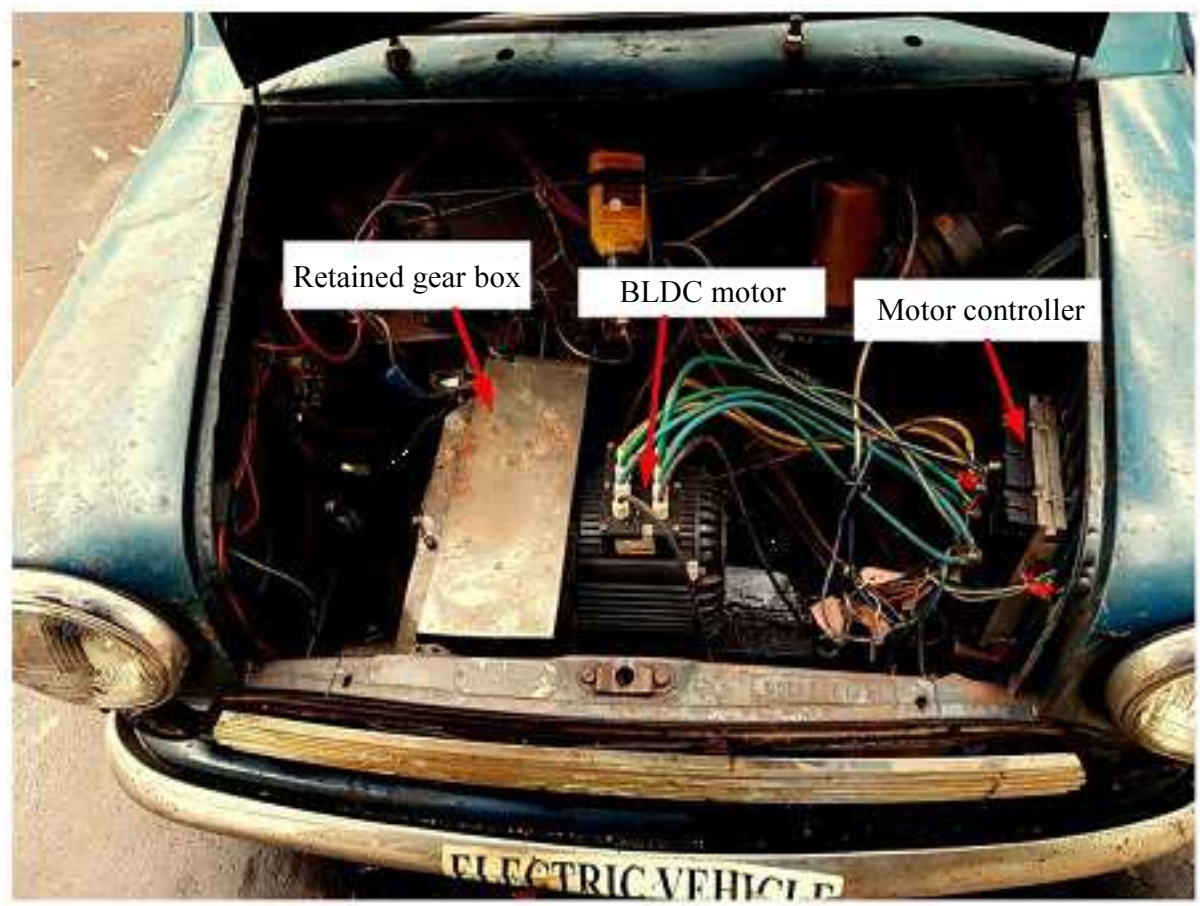

Fig. 2: Converted vehicle 
At the time intervals that the EV battery is connected to the output DC bus, the SC pack is charged to its rated voltage. Hence the SC pack always keeps its $\mathrm{SoC}$ in the range of its maximum and minimum limits. ADVISOR and Matlab Simulink software were used to obtain the EV battery current requirement and the corresponding speed of the vehicle in a UDDS cycle of the chosen vehicle model. Vehicle model is comprised of the body weight of the vehicle, weight of the Battery bank, SC pack weight and average weight of four people. The parameters, which are used for the simulation, are given in the Table 2. Results obtained from the ADVISOR simulation were used to simulate the Hybrid Energy Storage System model built on PSIM software. The current and the speed were input to the model using two lookup tables.

For acceleration, the energy should be given from the battery or the SC or from both of them to the DC Bus in the motor drive as required.

For the deceleration, switches are turned on according to the above algorithm to get the regenerative energy back to the energy storage devices. If the SC voltage is less than its rated predefined voltage value $(350 \mathrm{~V})$ and the deceleration is higher than the predefined value "b", then SC pack will absorb the energy loss of the vehicle during the deceleration and will be charged. If the $\mathrm{SC}$ voltage is more than the aforementioned rated predefined voltage value or the deceleration is lesser than the aforementioned predefined value, then the battery will be charged.

Table 2: Test parameters

\begin{tabular}{ll}
\hline Test Parameter & Value \\
\hline $\begin{array}{l}\text { Weight of the Vehicle (including } \\
\text { battery and super capacitor pack) }\end{array}$ & $1200 \mathrm{~kg}$ \\
Weight of passengers & $300 \mathrm{~kg}$ \\
Battery bank capacity & $66 \mathrm{Ah}$ \\
SC pack capacity & $10 \mathrm{~F}$ \\
SC pack initial voltage & $360 \mathrm{~V}$ \\
Battery initial terminal voltage & $355 \mathrm{~V}$ \\
Battery initial SoC & $100 \%$ \\
Acceleration threshold value (a) & $2 \mathrm{~m} / \mathrm{s}^{2}$ \\
Deceleration threshold value (b) & $-2 \mathrm{~m} / \mathrm{s}^{2}$ \\
\hline
\end{tabular}

In this research the data obtained for an EV for the UDDS cycle from the ADVISOR software is used in the analysis. Then that data is imported to the software PSIM and tests were carried out for the battery only mode as well as for the battery-super capacitor hybrid mode. For connecting the battery-super capacitor system, a novel algorithm and a system were introduced.

\section{Results}

The Austin Mini which was converted into a motor driven vehicle was tested in a pre-defined path within the university. The test cycle was defined so that the vehicle can be subjected to sudden accelerations, sudden decelerations and stop and go conditions. Those are the driving conditions which are mostly associated with the urban driving conditions. The speed, altitude and the speed of the vehicle during the test run was measured using data acquisition hardware (Fig. 3). The converted vehicle was subjected to stop and go conditions, sudden accelerations and decelerations, during its test drive cycle. The vehicle could perform all the required tasks within the expected time period. The simulations were performed for the drive cycle: Urban Dynamometer Driving Schedule (Fig. 4).

The addition of super capacitors gives the following results. As shown in the Fig. 5, battery terminal voltage variation span had been reduced after adding the SC pack. The reason for this can be further explained using Fig. 6. In Fig. 6, it can be observed that the high frequency current component of the DC bus had been absorbed by the SC pack. Hence the battery voltage is fluctuating on top of the SC pack voltage. The peaks of which the battery voltage previously had, had been reduced and the additional voltage had been absorbed by the SC pack. According to Fig. 7 it can be observed that the currents peaks drawn from the batteries had also been reduced. This results in making reduced stress on the batteries, thus extending the life time of the batteries. According to Fig. 8, a slight range extension can be observed after adding the SC pack.

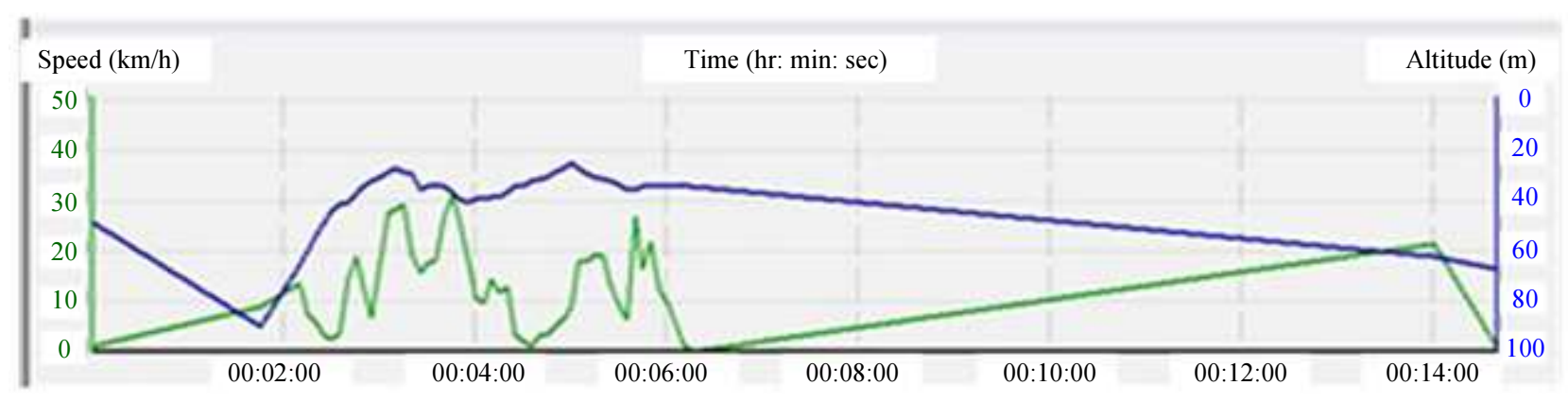

Fig. 3: Test drive results 


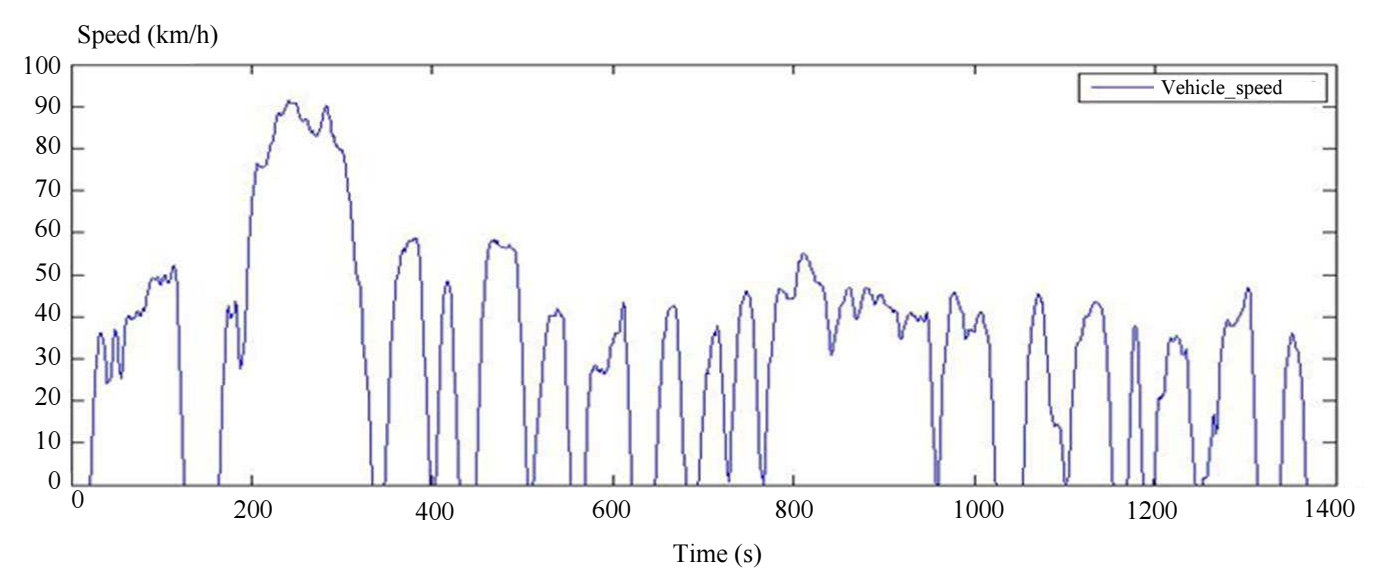

Fig. 4: Urban dynamometer drive schedule

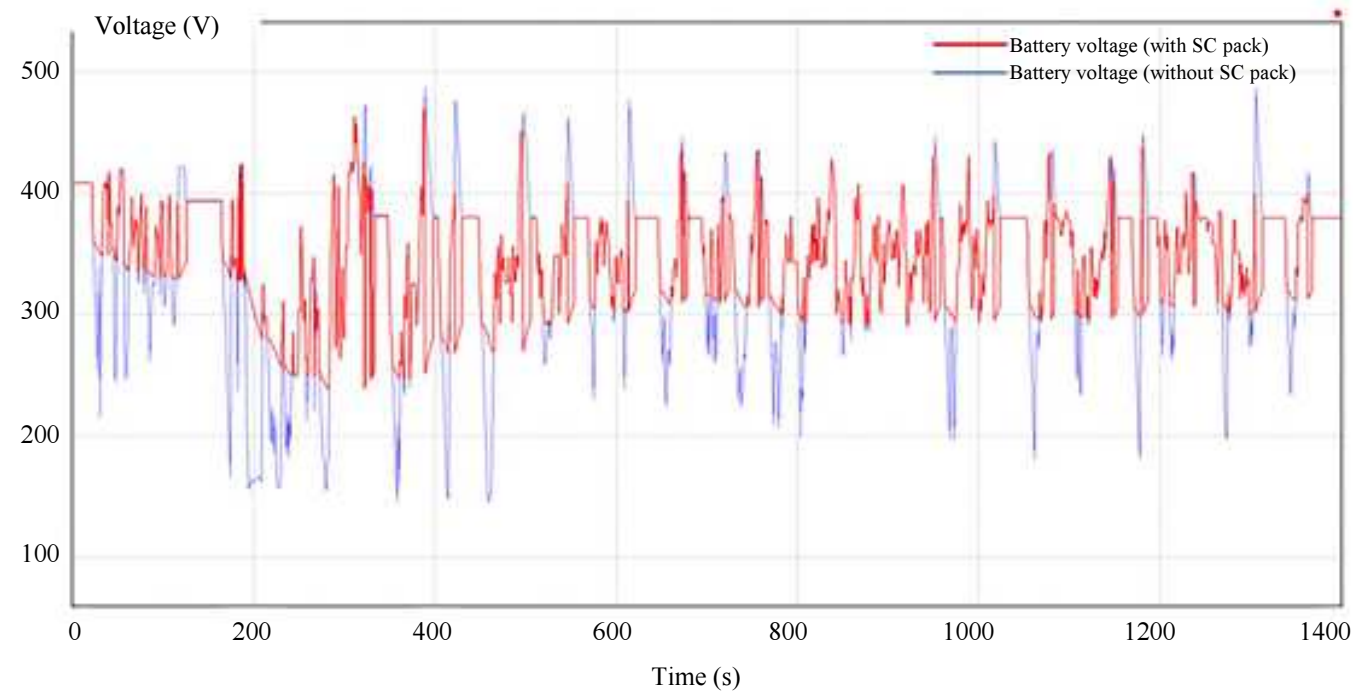

Fig. 5: Battery voltage (with and without SC pack)

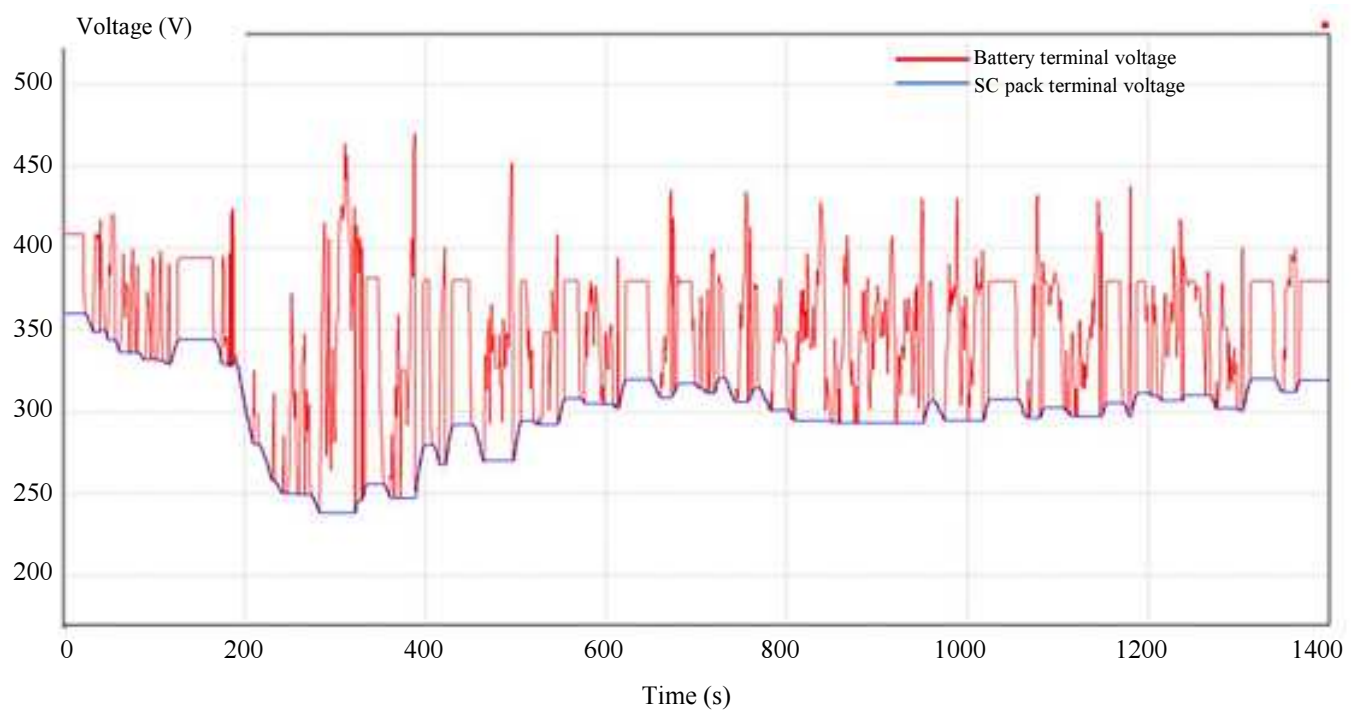

Fig. 6: Battery and SC pack voltages 


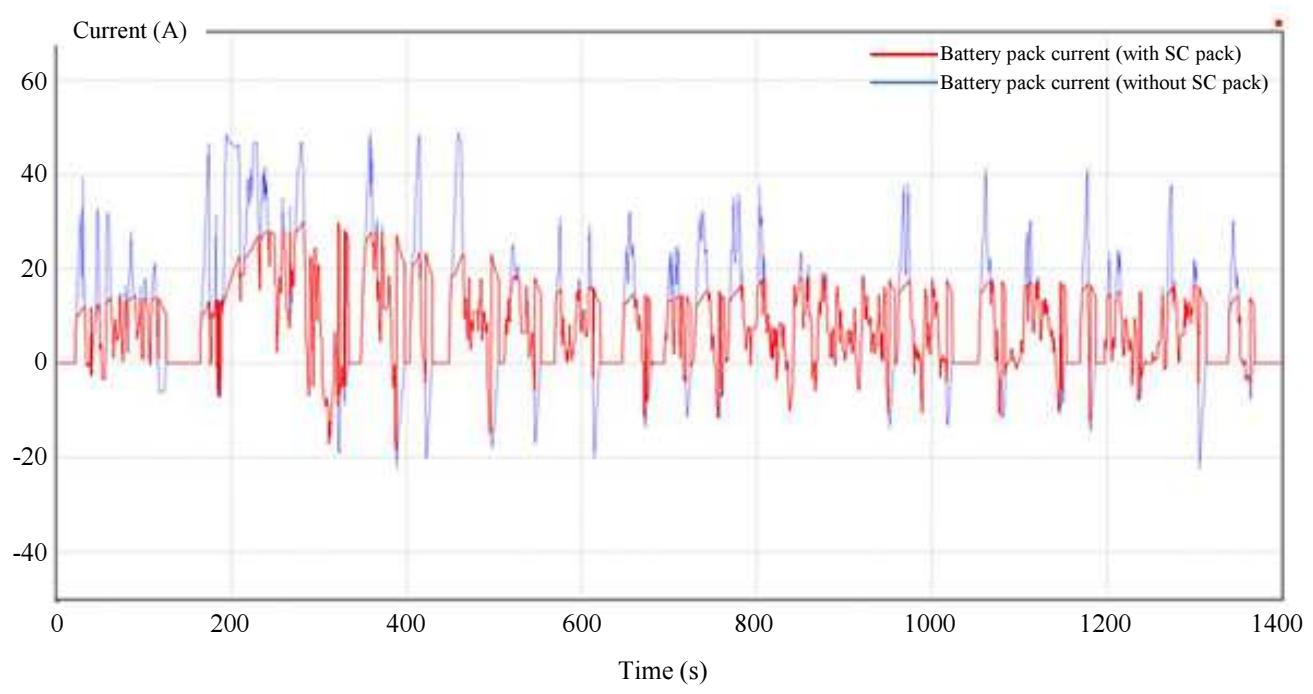

Fig. 7: Battery current (With and without SC pack)

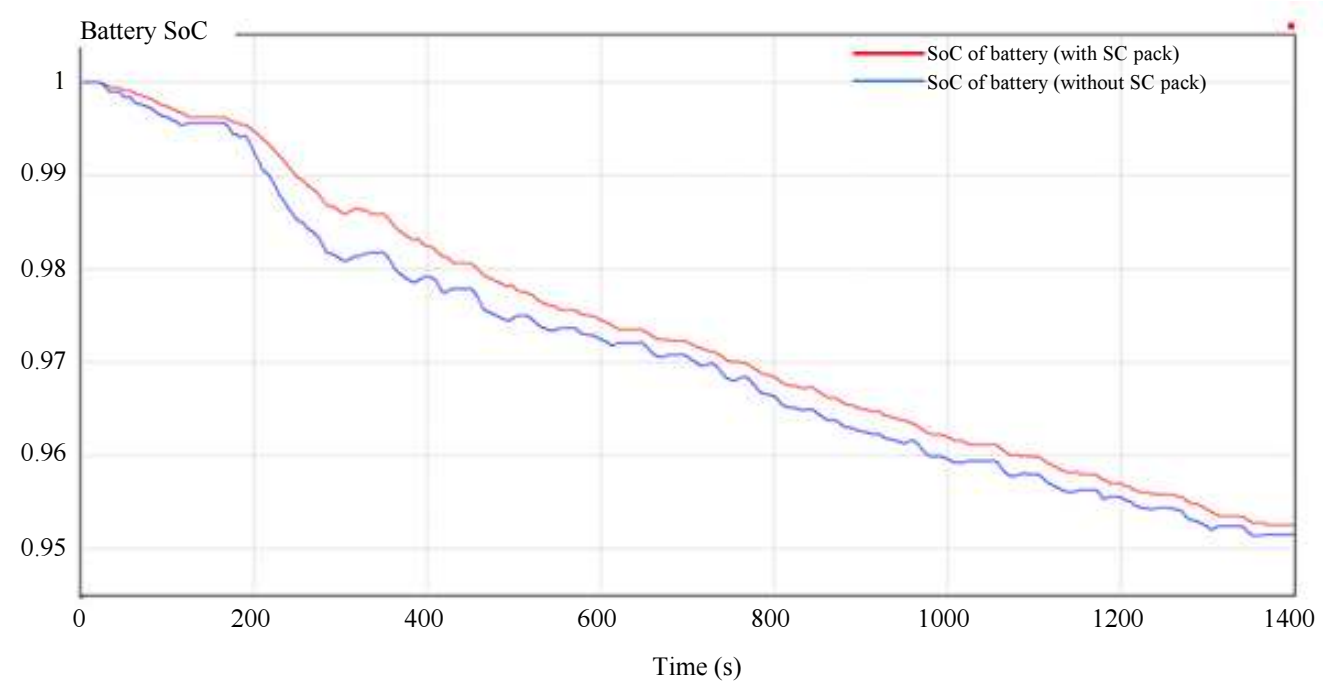

Fig. 8: SoC of batteries (With and without SC pack)

\section{Discussion and Conclusion}

As discussed above, it can be seen that the addition of super capacitors to the system had reduced the current which is drawn out from the batteries. The battery current has become much stabilized with the addition of super capacitors. Figure 7 clearly shows that the fluctuation of the battery power output has been reduced after adding super capacitors as a parallel energy storage device to the batteries. Since there are no sudden fluctuations of the battery power after the addition of a parallel energy storage system, the stresses which are acting on the batteries will be reduced, thus increasing the battery life and the performance.

The total energy lost during the braking cannot be recovered at the batteries because of the moderate charge discharge rate of Li-ion batteries. The majority of this lost energy can be recovered using a battery-super capacitor system. The additional energy stored in the capacitor bank can be extracted from regenerative braking. Through the ADVISOR and PSIM simulations it can be proven that the stresses on the battery bank can be reduces by having a super capacitor bank as an auxiliary power source.

The SoC of the batteries throughout the UDDS cycle are presented in Fig. 8. The two results are for SoCs with SC pack and without SC pack. The extension of the range of the vehicle is limited by the factors of the weight and the cost of the SC Pack. The nominal voltage of the battery pack for our design is $355 \mathrm{~V}$. Therefore the SC Pack voltage should also be around the value $355 \mathrm{~V}$ and in our case it is $360 \mathrm{~V}$. 
Since the commercially available super capacitors has a nominal voltage of $2.7 \mathrm{~V}$, to match up the battery nominal voltage when connecting them parallel, more than 130 super capacitors are needed to be connected in series. Then the total capacitance of the SC pack is reduced by a factor of 130 . (i.e., If the capacitance of a single super capacitor is $2000 \mathrm{~F}$, then the resultant capacitance of the system would be around $15 \mathrm{~F}$ ). In this research, to compensate the losses and discharges, the capacitance of the SC pack was taken as 10F. Because of the above limitation the advantage of the high capacitance of super capacitors cannot be fully utilized. Since the high cost of the super capacitors is a limiting factor too, when designing a battery-super capacitor hybrid system, one has to limit the number of capacitors that can be used in the system.

\section{Acknowledgement}

The authors acknowledge the support given by the University of Moratuwa and the Lanka Harness (pvt) Ltd. for this research.

\section{Authors' contributions}

Anuradha Herath, Pasan Gunawardena and Vimukthi Randeny: Performed laboratory experiments, data analysis and the software analysis of the research and also participated in writing the manuscript.

Sasiranga de Silva and Nirosh Jayawera: Provided the research topic, guided the research development and experimental panning.

\section{Ethics}

This article is an original research paper. There are no ethical issues that may arise after the publication of this manuscript.

\section{References}

Anderson, C.D. and J. Anderson, 2004. The Evolution of the Electric Vehicle. In: Electric and Hybrid Cars: A History, McFarland, pp: 21-106.

Brown, T.L., V.P. Atluri and J.P. Scmiedeler, 2014. A low cost hybrid drivetrain concept based on compressed air energy. Applied Energy, 134: 477-489. DOI: 10.1016/j.apenergy.2014.07.111

Burke, A., 2005. Energy storage in advanced vehicle systems. Proceedings of the Stanford University GCEP Advanced Transportation Workshop, (ATW' 05), California.

Cao, J., A. Emadi and S. Member, 2012. A new battery/ultracapacitor hybrid energy storage system for electric, hybrid and plug-in hybrid electric vehicles. IEEE Trans. Power Electron., 27: 122-132. DOI: 10.1109/TPEL.2011.2151206
DT, 2007. Transport statistics publications, the highway code: Typical stopping distances. Department for Transport, England, Scotland, Wales.

Embrandiri, M., D. Isa and A. Aheli, 2011. Performance of an electric vehicle conversion at the University of Nottingham, Malaysia. Woodhead Publishing, Cambridge.

Faiz, A., 1993. Automotive emissions in developing countries-relative implications for global warming, acidification and urban air quality. World Bank, 1818 H St. N.W., Washington, D.C. 20433, USA.

Guidi, G., T. Undeland and Y. Hori, 2009. Effectiveness of super capacitors as power-assist in pure EV using a sodium-nickel chloride battery as main energy storage. Proceedings of the International Battery, Hybrid and Fuel Cell Electric Vehicle Symposium, May 13-16, Stavanger, Norway.

Hannan, M.A., F.A. Azidin and A. Mohammed, 2014. Hybrid electric vehicles and their challenges; a review. Renewable Sustainable Energy Rev., 29: 135-150. DOI: 10.1016/j.rser.2013.08.097

Johnson, V., 2002. Battery performance models in advisor. J. Power Sources, 110: 321-329. DOI: $10.1016 / \mathrm{S} 0378-7753(02) 00194-5$

Ju, F., Q. Zhang, W. Deng and J. Li, 2014. Review of structures and control of battery-supercapacitor hybrid energy storage system for electric vehicles. Proceedings of the IEEE International Conference on Automation Science and Engineering, Aug. 18-22, IEEE Xplore Press, Taipei, Taiwan, pp: 303-318. DOI: $10.1109 /$ CoASE.2014.6899318

Kerns, B., T. Lindsay, T. Williams and W. Eberle, 2017. A control algorithm to reduce electric vehicle battery pack RMS currents enabling a minimally sized supercapacitor pack. Proceedings of the IEEE Transportation Electrification Conference and Expo, Jun. 22-24, IEEE Xplore Press, Chicago, IL, USA, pp: 376-380. DOI: 10.1109/ITEC.2017.7993300

Khaligh, A. and Z. Li, 2010. Battery, ultracapacitor, fuel cell and hybrid energy storage systems for electric, hybrid electric, fuel cell and plug-in hybrid electric vehicles: State of the art. IEEE Trans. Veh. Technol., 59: 2806-2814. DOI: 10.1109/TVT.2010.2047877

Lahyani, A., P. Venet, A. Guermazi and A. Troudi, 2013. Battery/supercapacitors combination in Uninterruptible Power Supply (UPS). IEEE Trans. Power Electron., 28: 1509-1522. DOI: 10.1109/TPEL.2012.2210736

Larmine, J., 2003. Electric Vehicle Technology Explained. 1st Edn., John Wiley and Sons, Oxford, ISBN-10: 0470090693, pp: 296.

Lu, S., K.A. Corzine and M. Ferdowsi, 2007. A new battery/ultracapacitor energy storage system design and its motor drive integration for hybrid electric vehicles. IEEE Trans. Veh. Technol., 56: 1516-1523. DOI: 10.1109/TVT.2007.896971 
Lukic, S.M., C.J. Banshal, F. Rodriguez and A. Emandi, 2008. Energy storage systems for automotive applications. IEEE Trans. Indust. Electr., 55: 2258-2267. DOI: 10.1109/TIE.2008.918390

Markel, T., A. Brooker, T. Hendricks, V. Johnsons and K. Kelly et al., 2002. ADVISOR: A systems analysis tool for advanced vehicle modeling. J. Power Sources, 110: 255-266.

DOI: 10.1016/S0378-7753(02)00189-1

Micah Ortúzar, D., 2010. Implementation and evaluation of an ultracapacitor-based auxiliary energy system for electric vehicles. Department of Electrical Engineering, Pontificia Universidad Católica de Chile, Santiago.

Mierlo, J.V., G Maggeto and P. Lataire, 2006. Which energy source for road transport in the future? A comparison of battery, hybrid and fuel cell vehicles. Energy Convers. Manage., 47: 2748-2760. DOI: $10.1016 /$ j.enconman.2006.02.004

Mukongo, M., 2010. Battery supercapacitor hybrid energy storage system. Keld LLC, Denver, Colorado.

Randeny, V.R., H.M.R.A. Herath, S. De Silva and N.D. Jayaweera, 2015. Development of an electric drive system for conventional automobiles. Proceedings of the International Research and Technical Symposium, (RTS' 15), Colombo, Sri Lanka, pp: 71-75.
Senger, R.D., 1998. Validation of ADVISOR as a simulation tool for a series hybrid electric vehicle. Virginia Polytechnic Institute and State University, Virginia.

Smith, W.J., 2010. Can EV (electric vehicles) address Ireland's $\mathrm{CO}_{2}$ emissions from transport? Energy, 35: 4514-4521. DOI: 10.1016/j.energy.2010.07.029

Thounthong, P., M. Hinaje and V. Chunkang, 2009. Comparative study of fuel-cell vehicle hybridization with battery or supercapacitor storage device. IEEE trans. Vehicular Technol., 58: 3892-3904. DOI: $10.1109 /$ TVT.2009.2028571

USEPA, 2005. Light-duty vehicle and light duty truckClean fuel fleet exhaust emission. US Environmental Protection Agency.

Vasques, S., S.M. Lukic, E. Galvan, L. Franquelo and J. Carrasco, 2010. Energy storage systems for transport and grid applications. Industrial Electron., 57: 3881-3895. DOI: 10.1109/TIE.2010.2076414

Wipke, M.C.D.B.K., 1999. Advisor 2.0: A Second. National Renewable Energy Laboratory, Colorado.

Zhao, P., Y. Dai and J. Wang, 2014. Design and thermodynamic analysis of a hybrid energy storage system based on A- CAES (adiabatic compressed air energy storage) and ESS for wind power applications. Energy, 70: 674-684.

DOI: $10.1016 /$ j.energy.2014.04.055 